\title{
Educación y Revolución Bolivariana. Una pobre educación para los pobres
}

\section{Education and Bolivarian Revolution. A Poor Education for the Poor}

\author{
Tulio Ramírez ${ }^{1}$ \\ Universidad Central de Venezuela \\ Universidad Católica Andrés Bello (Venezuela)
}

Recibido: 11-08-17

Aprobado: 18-09-17

\section{Resumen}

Se hace un balance de las políticas públicas educativas implementadas en Venezuela por la revolución bolivariana. El resultado demuestra que el interés ha sido utilizar la educación como mecanismo de cohesión ideológica en torno al proyecto político que orienta a la nación hacia el modelo del socialismo del siglo XXI. El control político de docentes, la ideologización de estudiantes, el intento de implementar diseños curriculares sesgados, el cerco presupuestario para doblegar a la universidad autónoma, así como la creación de misiones educativas que han servido demagógicamente para captar adeptos a favor del gobierno revolucionario, son algunas de las políticas que han llevado a la educación pública venezolana, cuyos usuarios son los sectores más pobres de la sociedad, a niveles cada vez más altos de precariedad académica, lo que permite concluir que la revolución ha terminado construyendo una pobre educación para los pobres.

Palabras-clave: Políticas públicas, Educación, Calidad Académica, Exclusión escolar.

\footnotetext{
${ }^{1}$ (tuliorc1@gmail.com). Sociólogo, Abogado, Magister en Relaciones Industriales, Doctor en Filosofía y Ciencias de la Educación con postdoctorado en Filosofía y Ciencias de la Educación. Profesor Titular de la Universidad Central de Venezuela y la Universidad Pedagógica Experimental Libertador, director del Postdoctorado en Filosofía y Ciencias de la Educación de la Universidad Central de Venezuela, director del Doctorado en Educación de la Universidad Católica Andrés Bello, ex Coordinador del Doctorado en Educación en la Universidad Central de Venezuela. 16 libros en el área de la sociología de la educación, sociología del trabajo y metodología de la investigación. 47 artículos publicados en revistas arbitradas e indizadas. Profesor invitado de la Universidad de Pereira y la Universidad Pedagógica y Tecnológica de Colombia (Colombia) y de la Universidad Técnica de Cotopaxi (Ecuador). Asesor de la Comisión de Educación de la Asamblea Nacional de Venezuela. Articulista del Diario Tal Cual desde 2010.
} 


\begin{abstract}
A balance is made of the public educational policies implemented in Venezuela by the Bolivarian revolution. The result shows that the interest has been to use education as a mechanism of ideological cohesion around the political project that guides the nation towards the model of 21 st century socialism. The political control of teachers, the ideologizing of students, the attempt to implement biased curricular designs, the budgetary fence to bend the autonomous university, as well as the creation of educational missions that have demagogically served to attract supporters in favor of the revolutionary government, are just some of the policies that have led Venezuelan public education, whose users are the poorest sectors of society, to constantly increasing levels of academic precariousness, which leads to the conclusion that the revolution has ended up developing a poor education for the poor.
\end{abstract}

Key-words: Public policies, Education, Academic Quality, School exclusion.

\title{
Introducción
}

La llamada revolución bolivariana que se impuso en Venezuela desde 1999 ha mantenido, como política de Estado, el interés por convertir a la educación en una suerte de "cabeza de playa" para imponer en las jóvenes generaciones los ideales del socialismo del siglo XXI. Desde el año 2001, cuando intentaron por vía de un Decreto Presidencial (Decreto 1011), destituir unilateralmente y sin procedimiento administrativo a docentes y directores de escuelas reacios a seguir las instrucciones del Despacho de Educación, se desataron reacciones de la sociedad civil que no solamente hicieron retroceder la aplicación del referido decreto, sino que prendieron señales de alarma sobre las verdaderas intenciones del gobierno en materia educativa.

De las políticas que más han generado controversia está la creación de las misiones educativas, los intentos de imponer diseños curriculares para educación primaria y secundaria comprobadamente ideologizados, la aplicación de los lineamientos para el sector esbozados en el inconstitucional Plan de la Patria, la ausencia de información sobre el tema de la calidad educativa, la elaboración de millones de textos escolares marcadamente sesgados y distribuidos gratuitamente en las escuela oficiales, los intentos por hacer de la educación privada una actividad económicamente insostenible, el cerco a las universidades autónomas a través de la asfixia presupuestaria y el cercenamiento de sus atribuciones autonómicas a través de la asunción unilateral e inconsulta de muchas de sus atribuciones legales por parte del gobierno. Sin embargo, 
la resistencia de la sociedad civil democrática a postergado en innumerables ocasiones estos intentos abiertos por convertir a la escuela en una prolongación de los núcleos de formación de cuadros políticos del partido de gobierno. Aunque, vale decir, el gobierno revolucionario ha avanzado mucho en sus pretensiones.

En este artículo se pretende mostrar algunas de estas políticas con la finalidad de evidenciar ante el mundo que, para la llamada revolución bolivariana, la educación nunca se ha asumido como mecanismo para el desarrollo y progreso individual y social y que, por el contrario, la misión que se le asigna es la de asegurar por parte de las generaciones que hoy día se están levantando, el apoyo y cohesión en torno a un proyecto político-partidista que pretende sustituir la democracia que se ha implantado en Venezuela desde 1958. El modelo político que se intenta implantar es similar a los socialismos autoritarios que han empobrecido a países de buena parte de Europa del Este y a países de la región, como es el caso del fracasado proyecto comunista de Cuba.

\section{Educación en Revolución. Misión estratégica: ideologizar, no educar}

Hugo Chávez siempre pensó a la educación como un arma para la guerra ideológica. Su proyecto político nunca la concibió como mecanismo para la formación de profesionales para impulsar el desarrollo científico y tecnológico de Venezuela, mucho menos para formar ciudadanos con valores democráticos que contribuyan a la convivencia social. Al asumir la educación como un espacio para el control político, se actuó en consecuencia. Las políticas públicas diseñadas desde 1999 apuntaron hacia la alineación de la educación a la esfera de lo que denominó Gramsci como "Hegemonía Cultural" (2007), es decir, contribuir a la internalización de los valores socialistas con la finalidad de generar la superestructura ideológica y política necesaria para cohesionar a la sociedad en torno al modelo que se ha pretendido instaurar en Venezuela, vale decir, el modelo socialista de corte militarista.

En las primeras de cambio, estas políticas se concentraron en el control de los maestros a través de la implantación del Decreto 1011 del año 2001. Con este decreto presidencial se creó la figura de los Supervisores Itinerantes, suerte de comisarios políticos del Ministerio de Educación, con la competencia de sancionar y destituir, sin procedimiento administrativo previo, tal como estable la Ley, a docentes y directores que sospechosos de no acatar las instrucciones ministeriales. Por supuesto, ese celo por el acatamiento, no era más que la excusa para, sin fórmula de juicio, destituir a quienes eran catalogados como "escuálidos" (el régimen cubano llama "gusanos" a sus opositores en Miami), 
o no afectos al régimen. Esta política generó la primera reacción de la sociedad civil que el gobierno de Chávez conoció. Bajo el lema "Con mis hijos no te metas", las calles de Caracas fueron testigos de las protestas de padres y representantes, quienes desde temprano advirtieron la indebida intromisión de estos supervisores nombrados ad hoc, en las escuelas privadas. Fue la primera derrota en la calle del gobierno. Finalmente, aunque el decreto no ha sido derogado, por la vía de los hechos el gobierno desistió de aplicarlo.

Otra de las políticas gubernamentales que se evidenciaron desde los primeros años de la revolución bolivariana fue la creación de gremios docentes paralelos a los existentes, con el fin de dividir el movimiento magisterial. Pero eso no sería un inconveniente dado que la democracia venezolana a través de sus leyes permite la libertad de asociación sindical. El asunto es que siendo un sindicato donde nunca se realizaron elecciones para elegir su Directiva, el gobierno lo reconoció como único vocero válido para la discusión de los contratos colectivos. Con esta maniobra digna de los regímenes fascistas, se marginaron a las federaciones gremiales.

\section{Las Misiones educativas o como ganar elecciones gracias a la demagogia}

En el año 2002 el país exigió al Consejo Nacional Electoral (CNE), organizar un referendo revocatorio del presidente Hugo Chávez. Se cumplía la mitad del período presidencial y por mandato constitucional, el pueblo podía solicitar esa revocatoria. Ya habían transcurridos los sucesos del llamado paro petrolero con sus secuelas de despidos de toda la masa crítica de la industria petrolera PDVSA.

El organismo electoral recurrió a todas las trabas posibles para evitar ese referendo. Esto permitió que Hugo Chávez implantara una serie de políticas tendentes a recuperar el favor popular e ir en mejores condiciones a la justa electoral. Así, para el año 2003 crea unos programas asistenciales que dio en llamar Misiones. El objetivo fue atender de manera directa algunas de las necesidades más inmediatas de la población. Una de ellas fue la Misión Barrio Adentro (Decreto del Ejecutivo No. 2745 de fecha 26-01-04), la cual consistía en instalar módulos de atención primaria en salud en las barriadas más depauperadas de la capital y en las zonas marginales de las ciudades más importantes del país. La falta de personal médico disponible en lo inmediato lo llevó a establecer un convenio con Cuba. A cambio de petróleo, Cuba enviaría médicos que prestarían atención a la población a cambio de un sueldo (buena parte de éste era pagado al gobierno cubano en dólares, quedando a los galenos una mínima parte en bolívares). Por supuesto, esta iniciativa le granjeó muchas simpatías al presidente ya que la atención gubernamental en el área a ese sector 
de la población se había deteriorado con el paso del tiempo por la insuficiencia de recursos y la mala administración de los pocos que había.

Otra de las iniciativas fue la creación de la Misión Robinson (Decreto del Ejecutivo No. 2434 del 02-06-03). Su objetivo, alfabetizar a la población que no había tenido la oportunidad de ingresar al sistema escolar formal. Al igual que con la Misión Barrio Adentro, el gobierno de Chávez estableció un convenio con Cuba, el cual proveyó de material audiovisual y facilitadores a cambio de ventajas en la venta de petróleo. Ambas misiones fueron impulsadas por un aparato propagandístico que, con ingenio y agresividad, posicionó en el inconsciente colectivo la idea de que el gobierno atendía de manera eficaz, y sin nada a cambio, a los pobres de Venezuela. Los resultados se vieron al momento de contarse los votos en el referendo revocatorio. El presidente Chávez obtuvo los suficientes para permanecer en el poder. Pero analicemos con un poco más de detalle lo referido a la Misión Robinson.

$\mathrm{El}$ aparato propagandístico del gobierno vendió la idea de un despliegue envolvente hacia todo el país por parte de los alfabetizadores. Se utilizaron las mismas técnicas propagandísticas que usaron los cubanos en su campaña de alfabetización del año 1961. Constantemente se veían por los medios de comunicación a los muchachos facilitadores, morral en ristre, alegres por la misión que llevaban adelante. En no pocas oportunidades transmitían escenas conmovedoras de supuestos alfabetizados, dando gracias a la revolución por haberles dado la oportunidad de conseguir la luz a través de las letras. Más de un país aliado congratulaba al gobierno revolucionario por tan hermosa iniciativa. El gobierno llegó a señalar en un acto público del año 2005 que la UNESCO había decretado a Venezuela como "Territorio Libre de Analfabetismo" y la colocaba como ejemplo para los pueblos del mundo.

Pero la mentira siempre ha tenido patas cortas. La propia UNESCO desmintió tal comunicado. En realidad, esta oficina dependiente de la ONU, lo que hizo fue transmitirle al gobierno venezolano el reconocimiento de los avances en materia de alfabetización. Sin embargo, las autoridades venezolanas sacaron provecho de tal parabién, colocándole como aderezo algo que nunca dijeron los expertos de la UNESCO. El investigador venezolano Luís Bravo ha catalogado este episodio como "La mentira pedagógica más grande jamás contada" (Bravo 2006, Ramírez 2009). Las cifras que se presentan a continuación rebelan que la afirmación de Bravo no es exagerada. En 2006 el para entonces ministro de educación, Aristóbulo Istúriz tuvo que admitir públicamente que la declaración de Territorio Libre de Analfabetismo no la otorgo el organismo internacional, sino que fue "una declaración soberana de Venezuela". 
Tabla 1

Alfabetización en Venezuela CENSOS del INE

\begin{tabular}{lcccc}
\hline Censo/ Año & Población & $\begin{array}{c}\text { Tasa de } \\
\text { alfabetización } \\
\text { según Censo }\end{array}$ & $\begin{array}{c}\text { Tasa de } \\
\text { analfabetismo }\end{array}$ & Analfabetos N \\
\hline 1961 & 7.869 .460 & 55,2 & 44,8 & 3.525 .518 \\
1971 & 11.093 .557 & 77,1 & 22,9 & 2.540 .424 \\
1981 & 15.515 .285 & 86.0 & 14 & 2.172 .139 \\
1990 & 19.501 .849 & 90,7 & 9,3 & 1.813 .671 \\
2001 & 24.631 .900 & 93,6 & 6,4 & 1.576 .441 \\
2011 & 28.946 .101 & 95,1 & 4,9 & 1.418 .350 \\
\hline
\end{tabular}

Fuente: Instituto Nacional de Estadística

Se podrá observar que, si bien para el año 2001 el analfabetismo en Venezuela alcanzaba un porcentaje de 6,4, para el año 2011, año del último censo en el país, el registro de analfabetas es de casi un 5\% (INE, 2011). A pesar de la millonaria propaganda, la enorme cantidad de recursos públicos que se erogaron para llevar adelante esa campaña y la firma de convenios leoninos con Cuba para intercambiar petróleo por servicios, el impacto real sobre la población analfabeta en Venezuela fue prácticamente imperceptible estadísticamente hablando. La UNESCO califica como superado el analfabetismo cuando la población con esta condición no es superior al 4\%. Las cifras hablan por sí solas, con el aditamento que no son independientes sino emanadas por un organismo oficial como es el Instituto Nacional de Estadísticas.

Si bien no se cumplió el cometido pedagógico, esta misión si contribuyó a lograr el objetivo electoral. Para 2017, 14 años después, la Misión Robinson es un programa casi en extinción, no porque hayan desaparecido los analfabetos, como falsamente insiste el gobierno (persiste en un 5\% de la población), sino porque su cometido político se agotó y porque con la caída de los precios del petróleo no hay recursos para mantener la burocracia que soportaba tal programa.

Es pertinente señalar que paralelamente a la solicitud de referendo que se inicia en febrero de 2003, Chávez dio a conocer no solo el decreto que crea a la Misión Robinson I (para alfabetizar) y II ( para completar la primaria en brevísimo tiempo); también crea la Misión Rivas (Resolución ministerial No. 47 del 09.06.2004), para culminar el Bachillerato en un lapso de 2 años, sin cursar asignaturas como Química, Física, Biología y Matemática; y la Misión Sucre (Decreto Presidencial Nro. 2604 de 09.09.2003), para cursar 
carreras universitarias en instalaciones ad hoc, con titulación certificada por universidades experimentales creadas por la revolución a partir del año 2005. Como se podrá observar se creó un circuito escolar paralelo al formal, con menos exigencias académicas, pero con el firme propósito de generar una clientela "satisfecha" por haber tenido la oportunidad de obtener un Título Universitario de muy baja estima en el mercado laboral (Ramírez, 2009).

\section{El Diseño Curricular: el caballo de Troya}

Los intentos fallidos de imponer diseños curriculares por parte de los gobiernos de Chávez y Maduro, han sido reiterativos. Desde el año 2007, siendo ministro de educación el Profesor Adán Chávez, hermano del difunto presidente, se dio inicio a esta política. En esa oportunidad se propuso la creación del Diseño Curricular para el Sistema Educativo Bolivariano. Su contenido, marcadamente ideologizante y propagandístico, fue inmediatamente denunciado por los gremios docentes y organizaciones no gubernamentales como Asamblea de Educación y la Federación Nacional de Padres (FENASOPADRES), así como por las universidades, los gremios docentes y las Academias Nacionales. La presión fue de tal magnitud que a pesar de que el ministro Chávez había prometido implantarlo para el comienzo del año escolar 2007-2008, el propio presidente Chávez lo engavetó, impidiendo que se materializara su implementación. Algunas de las conclusiones que se desprendieron del análisis de esta propuesta curricular, y que generó rechazo por parte de la sociedad venezolana, fueron los siguientes.

El Diseño Curricular propuesto estableció textualmente que su objetivo es la formación de un nuevo republicano afín con el nuevo modelo de sociedad que se quiere implantar en el país, a saber, el socialista no previsto en la constitución de 1999. En el área histórica había omisiones que llamaron la atención; por ejemplo, se omite para su estudio el período de la Dictadura del General Marcos Pérez Jiménez. De igual manera hay un vuelo rasante del período democrático que va de 1958 hasta 1999, sólo destacándose el Pacto de Punto Fijo como el "Pacto de la Oligarquía contra el Pueblo". Esto, evidentemente, es una interpretación descaradamente interesada de la Historia reciente. Se hace apología a los actos de gobierno de manera insistente, a tal punto que pareciera propaganda gubernamental más que un plan de estudios. Se evidenció una tendencia militarista y no civilista en la propuesta. Para el 4to. y 5to. Año de bachillerato se privilegian los temas ligados a la seguridad externa e interna y a la formación premilitar. En el área de Ciencias Sociales y Ciudadanía en vez de formar a los estudiantes en los mecanismos alternativos para la resolución de conflictos, se forman en "la parada militar, orden cerrado, 
movimiento pie firme, movimiento sobre la marcha" (MPPE 2006: 69). En este componente el $80 \%$ de los contenidos son de orden militar.

Esta experiencia no escarmentó al gobierno revolucionario. Por el contrario, años después se retomó esta idea y se propuso, en el año 2013, bajo la conducción del ministro de educación para la época, profesora Mariam Hanson, una nueva reforma denominada Diseño Curricular para la Educación Media General y Media Técnica. Este diseño no establecía el trabajo por las tradicionales asignaturas, sino por áreas de conocimiento que agrupaban diferentes disciplinas (MPPE 2013). Esta propuesta curricular generó las reacciones inmediatas de sectores académicos, padres y representantes y gremios magisteriales. Su contenido partidista y evidentemente ideologizante activó el rechazo de estos sectores. Considerar que el papel de la educación media era este documento dentro de una línea de inconstitucionalidad manifiesta.

Con el fin de dar un barniz democrático y de participación, se abrió desde el ministerio un periodo de supuestas consultas por vía de correo electrónico. Al igual que el diseño frustrado del ministro Adán Chávez de 2007, esta propuesta fue catalogada como marcadamente adoctrinante no solo por sus contenidos sino porque se fundamentaba en los lineamientos del inconstitucional Plan de Desarrollo Económico y Social Simón Bolívar 2013-2019, conocido como Plan de la Patria (entrevista a Tulio Ramírez y Leonardo Carvajal, El Universal del 07 de diciembre de 2013).

El Plan de la Patria, documento aprobado por la mayoría oficialista de la Asamblea Nacional (Parlamento venezolano), se quiso imponer como Ley de la República a pesar de no haber cumplido las formalidades para la creación de las leyes previstas en la Constitución Nacional. Entre otras inconstitucionalidades se destaca la que menoscaba el artículo 102 constitucional, el cual reza que la educación es "un servicio público y está fundamentada en el respeto a todas las corrientes del pensamiento, con la finalidad de desarrollar el potencial creativo de cada ser humano y el pleno ejercicio de su personalidad en una sociedad democrática..." (1999). Contrario a este principio democrático y pluralista, el Plan de la Patria, señala como uno de sus objetivos estratégicos:

"Preservar los valores bolivarianos liberadores, igualitarios, solidarios del pueblo venezolano y fomentar el desarrollo de una nueva ética socialista" (2013: 81).

A partir de este objetivo estratégico se le asigna a la educación la tarea de: "Adecuar los planes de estudio en todos los niveles para la inclusión de estrategias de formación de valores socialistas y patrióticos” (2013: 81).

Esto explica la persistencia por incorporar currículos y programas adoctrinantes y abiertamente propagandísticos a favor de la obra de gobierno y los valores políticos de la revolución. Como corolario de su gestión, la ministra Hanson promulgó además la Resolución 058, Resolución ministerial que 
trastocó la organización interna de la escuela, creando los Consejos Educativos y haciendo desaparecer la tradicional Sociedad de Padres y Representantes. Se crearon estos consejos con la participación de personas extrañas a la escuela, con la idea de menoscabar las atribuciones de los directores y de los padres organizados. El objetivo fue darle beligerancia en los asuntos de las escuelas a los miembros de los Consejos Comunales, organizaciones de base controladas por el Ministerio de las Comunas y conformadas por miembros del Partido de Gobierno. Es una manera eficaz de control de los espacios escolares, acorde con la vieja idea del control político sobre docentes, directivos y estudiantes. Así entonces, el control no se quedaría solo en la penetración ideológica a través de los contenidos impartidos, sino también a través de las decisiones administrativas de cada plantel.

Una vez destituida la ministro Hanson a finales de 2014, no se volvió a hablar del Currículo Nacional Bolivariano, ni de los resultados de la consulta por internet. Pareciera que los vaivenes del poder afectaban las políticas educativas. En esta época de revolución con los ministros se van también sus políticas o, por lo menos, sus iniciativas estratégicas. Para comienzos del año 2015 fue designado como nuevo ministro de educación, el joven abogado Héctor Rodríguez. Siguiendo la tradición de sus predecesores, retomó la idea de transformar la educación venezolana y organizó lo que se llamó la Consulta Nacional por la Calidad de la Educación. Fue una consulta que, según el propio ministro, cubrió a por lo menos a 7 millones de venezolanos en todo el país. Aunque nunca se conoció a ciencia cierta a quienes consultaron, se dio a conocer un informe sobre los resultados de la misma. Entre las conclusiones de esta consulta, de acuerdo a lo reportado por el ministro, se solicitaba que se propusiera un nuevo diseño curricular para la Educación Media (Bachillerato) y Educación Técnica (CERPE 2015).

Durante el año 2016 corrieron por las redes, por lo menos 4 versiones oficiales de este nuevo currículo. Inclusive se habló de ensayos pilotos en algunos liceos del país. Como suele suceder, nunca se supo a ciencia cierta en cuales liceos se implementó, y mucho menos los informes resultados de esa prueba. Finalmente se dio a conocer la propuesta, la cual variaba muy poco de la hecha durante la gestión de la profesora Hanson. Los más perspicaces aseguraron que la Consulta Nacional lo que hizo fue convalidar y darle legitimidad a un diseño que ya estaba elaborado años antes.

Vale la pena hacer referencia a la estructura de este diseño. En primer lugar, eliminó las tradicionales asignaturas y los sustituye por áreas de formación que integran de manera transdiciplinaria los contenidos de las disciplinas afines, lo que supone retomar la propuesta del diseño de 2013, arriba comentada. Ahora bien, los contenidos de cada área de formación se extraen de un conjunto de temas preestablecidos en el diseño curricular. Los profesores deben tratar los 
temas desde las diferentes perspectivas disciplinarias que conforman el área de formación. Así, por ejemplo, en ciencias naturales cuando se estudie el petróleo, debe abordarse desde la óptica de la química para conocer su estructura molecular, desde la óptica de la Biología para estudiarlo como fósil, desde la Física para conocer cómo se extrae del fondo de la superficie y desde la óptica de la Geografía para conocer su ubicación y desde la óptica de la Geografía Económica para conocer su valor estratégico en el desarrollo del país. Como se podrá observar se requiere un docente formado desde la transdisciplinariedad. Leamos lo que dice el documento oficial sobre las características que debe tener un profesor de ciencias naturales.

En ese sentido se plantea el área "educación en ciencias naturales" como un espacio de integración de saberes aportados por las diferentes disciplinas que la conforman, tales como: Biología, Química, Física, Ciencias de la Tierra, Antropología, Tecnología, Economía, Política, Salud, Educación, Pedagogía, Didáctica General, Didácticas Específicas, Currículo, Planificación, Evaluación, entre otras, que de acuerdo a distintos niveles de integración: intradisciplinar, interdisciplinar, transdisciplinar, cosmogónico, cosmológicos, pachamámicos, pluriversales, entre otros, permitan a las y los estudiantes disponer de suficientes oportunidades (vivencias, experiencias y querencias), para reflexionar acerca de los valores educativos que impregnan los saberes científicos, populares, ancestrales y tecnológicos en el contexto histórico, social y cultural en el que se desarrollan y así lograr una mejor comprensión de la naturaleza de la ciencia y las tecnociencias contemporáneas y su vinculación con la vida y la cotidianidad... (MPPE 2015: 85).

De acuerdo con esta particular visión se requiere un profesor con una formación y conocimientos "pluriversales" y "pachamanicos" (i¿?ं), que solo existe en la mente de los "expertos" que diseñaron este currículo. Tal despropósito solo es explicable si se asume como una medida desesperada para cubrir el tantas veces denunciado déficit de profesores en ciertas disciplinas, debido a los miserables sueldos y los exiguos beneficios sociales han hecho de la profesión docente en Venezuela, una de las menos solicitadas como opción de estudio y de trabajo.

A pesar de la imposibilidad de conseguir cifras oficiales que informen sobre el total de profesores que se necesitan para cubrir áreas como Física, Química, Biología, Matemática, Castellano e Inglés, se especula que hacen falta no menos de 5000 para paliar la situación. Sin embargo, el número de egresados en estas áreas en los Institutos Pedagógicos cada año es menor (en el año 2016 egresaron del Instituto Pedagógico de Caracas solo 3 profesores de Matemática y 10 profesores de Biología). Es importante anotar que el sociólogo venezolano Tomás Páez reporta en su investigación sobre la diáspora de venezolanos en el mundo, que para finales de 2014 habían salido del país 
más de un millón seiscientas mil personas, siendo en su mayoría profesionales universitarios (Páez 2015).

Para el período escolar 2017-2018 ha circulado en las redes sociales la instrucción por parte de las autoridades educativas de volver al currículo anterior de educación media. Esta medida al parecer fue tomada por el nuevo ministro de Educación, sociólogo Elías Jaua. De esto se evidencian tres cosas, no hay continuidad administrativa en la burocracia revolucionaria, la persistente práctica ministerial de emitir sus resoluciones e instrucciones por vía de las redes sociales y no por las vías formales; y, nuevamente se fracasa en términos de imposición de diseños curriculares. Sin embargo, en esta oportunidad pareciera que además de la presión de la sociedad civil, es debido a la inaplicabilidad de un diseño que técnica y pedagógicamente estuvo muy mal concebido. Seguramente no se conocerá el informe técnico de evaluación de esta experiencia fallida, es parte del oscurantismo que ha caracterizado a la gestión gubernamental de la revolución.

\section{La Colección Bicentenario. Textos escolares para adoctrinar, no para enseñar}

La utilización del texto escolar como vehículo deliberado de transmisión de contenidos ideológicos se acentúa cuando estos se elaboran y producen en contextos de regímenes con vocación autoritaria o francamente dictatoriales, o en el otro extremo, exageradamente populistas. Solo como referencia y sin pretender abundar en detalles, vale la pena señalar los textos escolares producidos durante el régimen nazista. En ellos se exaltaba la raza aria a tal extremo que, de manera dolosa, no se dejaba espacio para mostrar la diversidad étnica y cultural que convivía en la Alemania de entonces. Esta manera de usar los textos escolares también tuvo su réplica en los países comunistas. Estas prácticas en pleno siglo XXI no han cesado. Casos como el de Cuba y Corea del Norte son quizás de los más emblemáticos cuando se trata de indagar sobre el uso abusivo de los textos escolares. En el caso de los países fundamentalistas donde impera la intolerancia religiosa, la educación se ha convertido en un obstáculo para el libre pensamiento y los textos escolares con sus contenidos unidimensionales se han convertido en su arma más expedita.

América Latina no ha escapado a esta realidad. En la Argentina peronista los textos escolares fueron utilizados para potenciar el carisma de Perón y su esposa Evita. No solo se usaban ilustraciones con la imagen de ambos personajes, sino también se utilizaba sus nombres en el contenido de las lecciones. Era frecuente ver en libros de primeras letras, contenidos como " $M i$ papá y mi mamá me aman, Perón y Evita me aman”. En el caso de Cuba, luego 
de la revolución de 1958, el gobierno monopolizó la producción editorial de textos escolares. El resultado, textos escolares con un claro sesgo ideológico a favor del régimen, la exaltación de la figura de Fidel Castro y de las bondades de la revolución. Este es el más claro ejemplo del uso de los textos escolares como herramientas políticas de adoctrinamiento (Aguirre, Carvajal, Ugalde y Ramírez 2015; Ramírez 2012; Ramírez 2009).

El caso que nos ocupa, la Venezuela de la revolución bolivariana, no escapó a la tentación de recurrir a los libros de texto para "vender" la imagen del líder del denominado Socialismo del Siglo XXI. Sin embargo, es bueno aclarar que, si bien se trata de un régimen profundamente sesgado hacia la ideologización, cuestión reivindicada públicamente por sus connotados líderes, fue solo hasta el año 2011 cuando asumió como política pública la elaboración y distribución gratuita de los textos escolares para las escuelas y liceos dependientas del Estado (Ramírez 2012).

El Gobierno del Presidente Chávez justificó la medida de la elaboración y distribución gratuita de textos escolares con tres argumentos: a) los textos escolares no responden a los lineamientos del Plan Estratégico Simón Bolívar 2007-20012; b) No es coherente con el currículo de la educación bolivariana; $y, c)$ La carencia de un medio de enseñanza fundamental que apoyará a los docentes en la conducción del proceso educativo en las aulas, coherente con el fin de la educación (MPPE; 2011). Este último argumento se cae por su propio peso dada la constatable proliferación de textos escolares producidos por las editoriales privadas que inundaron sin ningún control por parte del Gobierno Nacional, el mercado venezolano por lo menos hasta el año 2011.

La distribución de los textos de la Colección Bicentenario para el período escolar 2011-2012, se realizó sin la previa revisión de los maestros y mucho menos de investigadores ligados a la academia. Fue a comienzos del año 2012 cuando se hacen las primeras denuncias sobre el sesgo ideológico de algunos de estos textos. Es de resaltar que fueron precisamente los contenidos referentes a la historia reciente de Venezuela que aparecen en el texto "Venezuela y su gente". Ciencias Sociales 6to. Grado (Bracho y León 2011), los que encendieron las alarmas. Al decir de la historiadora Inés Quintero "uno de los problemas fundamentales de estos libros es la orientación política y la concepción didáctica que están presentes en el tratamiento de los temas y problemas relacionados con la historia y su abierta distancia con las más recientes tendencias que, desde la última década del siglo pasado, han procurado enriquecer y problematizar la enseñanza de la historia" (2014: 1).

Veamos algunos de los contenidos más claramente sesgados del texto de Ciencias Sociales arriba reseñado y que provocaron la reacción adversa de la sociedad civil venezolana: 
a) Desbalance en el tratamiento de los períodos presidenciales en favor de Chávez. De un total de 46,5 páginas dedicadas a describir diez (10) períodos gubernamentales (páginas 102 a 147), le dedican a Chávez y a su gobierno un total de 22,5 páginas $(48,8 \%$ ), dejando el resto para tratar 9 presidencias previas.

b) Se glorifica la lucha armada de los años 60 llevada adelante por jóvenes con la intención de emular a la triunfante revolución cubana. Se trata como una rebelión justa y heroica de jóvenes idealistas, reprimida injustamente por gobiernos capitalistas. Esto, desde el punto de vista jurídico, no es otra cosa que apología del delito (Bracho y León 2011: 102-113).

c) Se omiten episodios públicos y notorios ya registrados por la Historia nacional como la invasión de guerrilleros cubanos enviados por Fidel Castro para apoyar a la guerrilla venezolana en su intento por tomar el poder por las armas.

d) La revuelta de 1989 conocida como El Caracazo se trata como rebelión popular y origen de las asonadas del 4 de febrero (4F) y 27 de noviembre $(27 \mathrm{~N})$ de 1992, intentos frustrados de Golpe de Estado liderados por Hugo Chávez. Se intenta en el texto establecer un hilo conductor entre ambos acontecimientos un poco artificiosamente, ya que algunos de los que participaron con Chávez en los intentos de Golpe de Estado en 1992, participaron activamente, siendo militares activos, en la represión desatada contra la población durante el llamado Caracazo (Ibid.: 120).

e) El $4 \mathrm{~F}$ y el $27 \mathrm{~N}$ se califican como rebeliones heroicas y no como intentos de Golpes de Estado. En la manía por reinterpretar los hechos históricos, se intentan justificar estas intentonas como actos épicos y heroicos históricamente justificados ya que, de acuerdo a la particular manera de interpretar la historia, constituirían el preludio de la revolución bolivariana (Ibid: 123).

f) Se hace una versión interesada de los sucesos del 11 de abril de 2002, cuando el presidente Chávez enfrenta una gran protesta frente al Palacio de Gobierno y renuncia a la presidencia por la presión militar. Se omiten hechos conocidos como la actuación de los llamados pistoleros de Puente Llaguno, quienes en apoyo al gobierno dispararon contra los manifestantes durante los sucesos del 11 de abril, la presencia de francotiradores apostados en las cercanías del Palacio de Gobierno y el llamado del presidente Chávez a implementar el Plan Ávila, que supone la salida del ejército a las calles para reprimir al pueblo opositor. Otro hecho de singular importancia es que se omite en el texto la actuación del General en Jefe Lucas Rincón anunciando en cadena nacional la renuncia del presidente Chávez (Ibíd.: 127-129).

Esto es solo muestra de la manera como se utiliza un texto escolar para contar la Historia de una manera interesada, poco apegada a los hechos y sin la orientación de algún principio ético ni pedagógico. El gobierno ha manifestado 
de manera reiterada su intención de adoctrinar a los jóvenes estudiantes venezolanos, prueba de ello fue la aseveración del hoy vicepresidente de la República, Profesor Aristóbulo Istúriz, quien, siendo Ministro de Educación, acunó en una declaración a los medios de comunicación dada en 2006, la siguiente frase: "En educación estamos ideologizando, ¿y qué?".

En la Consulta por la Calidad Educativa organizada por el ministro Héctor Rodríguez en febrero de 2014, se trató el tema de los textos escolares de la Colección Bicentenario. Se le prometió al país que serían revisados en función de las críticas recibidas. Para sorpresa de todos en junio de ese año se hizo una nueva edición. Al revisar el texto de Ciencias Sociales para 6to. Grado encontramos que más allá de unos pequeños retoques de redacción, permanecen los mismos errores, tergiversaciones y omisiones encontradas en la edición anterior, así como la misma propaganda política a favor de la obra de gobierno de Chávez. Es interesante señalar que además de la persistencia de los mismos errores, en esta nueva edición se invisibiliza a las ONG en cuanto al papel que jugaron ayudando a las víctimas de la revuelta por el aumento del precio del pasaje de transporte público en 1989, también conocida como el Caracazo (Ramírez 2015). Contrastemos las dos ediciones, la de 2011 y la de 2014.

\title{
Texto Nro. 1
}

Venezuela y su Gente. Ciencias Sociales 6to. Grado. 1ra. Edición. 2011. p. 121:

\footnotetext{
"También dejó como saldo la solidaria unión de familiares de las víctimas, quienes junto con algunos organismos no gubernamentales (ONG), se empeñaron en localizar muchos cadáveres enterrados en fosas comunes, cuya existencia negaba el gobierno" (Bracho y León 2011: 121).
}

Ahora observemos como cambia la redacción en la edición, supuestamente corregida, del año 2014.

\begin{abstract}
"El Caracazo dejó además un elevado saldo de heridos, prisioneros, ruina de pequeños propietarios de negocios, llanto de familiares de las víctimas cuyos cadáveres desaparecieron y llanto de familiares de quienes sí pudieron recibir cristiana sepultura. También dejó como saldo la solidaria unión de familiares de las víctimas, quienes, se empeñaron en localizar muchos cadáveres enterrados en fosas comunes." (Bracho y León 2014: 121).
\end{abstract}

Indudablemente que la posición vigilante frente a la violación de los Derechos Humanos por parte de las ONG en el país y su denuncia permanente en los organismos internacionales, han hecho cambiar la postura del gobierno frente a las mismas. Eso explicaría como, de un plumazo, se borraron del texto de Ciencias Sociales de 6to grado distribuido en 2014, la mención a estas 
organizaciones. Al resultar incomodas estas $\mathrm{ONG}$, por sus posiciones valientes, el gobierno no hace otra cosa que desaparecerlas de los libros de historia.

Así siempre ha sido la llamada Historia Oficial en los sistemas autoritarios y no democráticos, se narra y se acomodan los acontecimientos dependiendo de las conveniencias e intereses del régimen. Al final, pareciera que la intención es reconstruir la Historia y no enseñar la Historia (Ramírez 2016).

\section{Las Fuerzas Armadas refuerzan la ideologización}

Como corolario de ese proceso continuado de ideologización en la escuela a través de los programas pret a porter que no tienen nada que ver con los programas y contenidos vigentes y los textos escolares de la Colección Bicentenaria, se suma la intención de la Fuerza Armada de servir de coadyuvante para lograr los objetivos estratégicos del llamado Plan de la Patria en cuanto a lograr que el sistema educativo sirva de acicate para adoctrinar en los valores socialistas a los niños venezolanos. Nos referimos específicamente a instructivo N. ${ }^{o}$ 001-16, del Ministerio de la Defensa y el CEOFANB (Centro Estratégico de Operaciones de las Fuerzas Armadas Bolivarianas de Venezuela), fechada el 07 de marzo de 2016, donde exigen a los comandantes cumplir la tarea de inculcar la ética y la disciplina socialista a los estudiantes de educación y a las unidades operativas de la FANB a través de la campaña motivacional "El Soldado Valiente Bolivariano 2016" (San Blas 2016).

Esta campaña que, de acuerdo a este instructivo, deben llevar adelante los efectivos militares en el seno de las instituciones escolares, se centraría en "incentivar la creatividad, la identidad nacional y la conciencia de servir a la patria, preservar en lo más íntimo de los niños, niñas y jóvenes el amor a los libertadores y hombres en armas", según señala en el Diario El Nacional de fecha 18 de abril de 2016 en reportaje del periodista Hernán Hugo Galicia, quien manifiesta haber tenido acceso a ese documento de unas 20 páginas (2016). Por supuesto, la figura de Hugo Chávez será de las más exaltadas, junto a Bolívar, Zamora y otros caudillos militares del santoral chavista.

Esta campaña, que tuvo una duración de 7 meses, se llevó a cabo en circunstancias en las que, al igual que el gobierno del presidente Nicolás Maduro, las Fuerzas Armadas Nacionales contaban con un precario apoyo o simpatía de parte de la ciudadanía. Los escándalos de narcotráfico donde han estado involucrados militares, las acusaciones de corrupción y la actitud represiva contra la disidencia, han colocado a esta fuerza en los más bajos niveles de popularidad desde hace por lo menos 60 años. Sin embargo, se advierte que además de ser una estrategia para intentar recuperar el apoyo de la ciudadanía, se convirtió en un mecanismo de adoctrinamiento a favor del 
proyecto político e ideológico impulsado por la revolución bolivariana. Esta campaña se inscribió dentro de uno de los objetivos específicos previstos en el presupuesto nacional para 2016 que involucraba directamente a las Fuerzas Armadas Nacionales, a saber: "Apoyar el desarrollo del currículo nacional bolivariano, así como también contribuir a la formación del nuevo ciudadano con conciencia socialista, sentido patriótico de identidad nacional, y defensores de la soberanía y seguridad de la Nación" (Ley de Presupuesto 2016: 08-05). A confesión de parte, relevo de pruebas. Este objetivo también está alineado con el Plan de la Patria 2013-2019 en cuanto a utilizar al sistema educativo como instrumento para formar en la ética socialista como objetivo estratégico.

\section{Dinámica matricular en Venezuela. En revolución los pobres se gradúan menos}

Una de las banderas que ha ondeado la revolución bolivariana a lo largo de los 18 años de gestión gubernamental ha sido la de la inclusión en la escuela. En el discurso y la propaganda oficial se habla de una deuda con el pueblo venezolano que ha sido saldada. Las cifras presentadas por el gobierno chavista van acompañadas con epítetos que magnifican los logros en esta materia. Se dice que Venezuela es el país donde se le han dado más oportunidades de estudio a la población pobre y que este fenómeno solo es comprable con las cifras aportadas por los países más desarrollados del mundo. Así entonces, se habla de un "Milagro Educativo".

Algunas de las cifras aportadas por la propaganda gubernamental señalan que gracias a la Misión Alfabetizadora Robinson se había enseñado a leer a 1,5 millones de personas. Se insiste también en que para el año 2004, 600.000 estudiantes se habían inscrito en los programas de la Misión Ribas para obtener su Título de educación secundaria en un par de años. Por otra parte, el gobierno declaró en 2013 que más de 700.000 personas habían pasado por la Misión Sucre con el fin de cursar estudios universitarios. Bravo (2006) ha manifestado que este sistema educativo paralelo y sin control directo de la institucionalidad en materia educativa, infla de manera importante las cifras sobre matrícula en Venezuela. Pero veamos a continuación la dinámica de la matrícula escolar desde 1999, y el efecto que sobre ellas tuvieron las misiones educativas a partir del 2003, año de su creación. 
Tabla 2

Matrícula escolar preuniversitaria (incluyendo las Misiones Educativas) y Población Total en Venezuela

(1999-2016)

\begin{tabular}{cccccc}
\hline Año & $\begin{array}{c}\text { Matricula } \\
\text { total }\end{array}$ & $\begin{array}{c}\text { Vari- } \\
\text { ación }\end{array}$ & Población Total & Variación & $\begin{array}{c}\text { \% de la } \\
\text { Matrícula con } \\
\text { respecto a la } \\
\text { población }\end{array}$ \\
\hline 1998 & 7.008 .692 & 3,2 & 23.242 .435 & 2 & 30,2 \\
1999 & 7.029 .477 & 0,3 & 23.706 .711 & 2 & 29,7 \\
2000 & 7.303 .155 & 3,9 & 24.169 .744 & 2 & 30,2 \\
2001 & 7.814 .371 & 7 & 24.631 .900 & 1,9 & 31,7 \\
2002 & 8.253 .735 & 5,6 & 25.093 .337 & 1,9 & 32,9 \\
$2003 *$ & 10.651 .645 & 29,1 & 25.553 .504 & 1,8 & 41,7 \\
2004 & 12.950 .267 & 21,6 & 26.127 .351 & 2,2 & 49,6 \\
2005 & 13.690 .841 & 5,7 & 26.577 .423 & 1,7 & 51,5 \\
2006 & 13.954 .105 & 1,9 & 27.030 .136 & 1,7 & 51,6 \\
2007 & 11.281 .506 & $-19,2$ & 27.483 .208 & 1,7 & 41 \\
2008 & 11.209 .325 & $-0,6$ & 27.934 .783 & 1,6 & 40,1 \\
2009 & 10.639 .590 & $-5,1$ & 28.384 .132 & 1,6 & 37,5 \\
2010 & 10.693 .529 & 0,5 & 28.833 .845 & 1,6 & 37,1 \\
2011 & 10.861 .752 & 1,6 & 28.946 .101 & 1.4 & 37,5 \\
2012 & 10.971 .482 & 0,1 & 29.601 .112 & 1,1 & 37,7 \\
2013 & 10.794 .091 & $-1,6$ & 30.110 .365 & 1,7 & 35,8 \\
2014 & 10.664 .924 & $-1,2$ & 30.620 .404 & 1,7 & 34,8 \\
2015 & 10.662 .641 & -0.01 & 30.620 .404 & 0 & 35 \\
2016 & 10.541 .845 & -1.0 & 31.028 .637 & 1.0 & 33,9 \\
\hline & Anno & $\mathbf{1}$ & & \\
\hline
\end{tabular}

Año de creación de las Misiones Educativas

Fuente: Memoria Educativa de Venezuela

Se muestra que a partir de la creación de las misiones educativas en el año 2003, hay un incremento importante de la matrícula total de estudiantes incorporados a la educación preuniversitaria y universitaria. Este crecimiento se mantiene sostenido hasta el 2006. A partir del 2007 hasta el año 2016 se observa un decrecimiento moderado que más bien indica cierto estancamiento, a pesar de que la población total se ha incrementado de manera importante (de 
23 millones en 1999 a 31 millones en 2016 de acuerdo a proyecciones a partir del censo del año 2011).

Veamos ahora las cifras correspondientes a la dinámica matricular desde 1999 hasta 2016 sin tomar en cuenta las misiones ni la matrícula universitaria. Se presentan las cifras totales, pero también, de manera discriminada, las cifras correspondientes a la educación oficial y la educación privada. Veamos.

Tabla 3

Matrícula escolar en Venezuela (sin las misiones educativas ni universidades) (1998-2016)

\begin{tabular}{cccc}
\hline Año & Total & Oficial & Privado \\
\hline $1998-9$ & 6.233 .127 & 5.009 .938 & 1.223 .189 \\
$1999-0$ & 6.487 .446 & 5.308 .790 & 1.178 .656 \\
$2000-1$ & 6.961 .421 & 5.685 .389 & 1.276 .032 \\
$2001-2$ & 7.372 .234 & 6.053 .952 & 1.318 .282 \\
$2002-3$ & 7.402 .665 & 6.118 .347 & 1.284 .318 \\
$2003-4$ & 8.036 .957 & 6.750 .393 & 1.286 .564 \\
$2004-5$ & 8.071 .959 & 6.730 .557 & 1.341 .402 \\
$2005-6$ & 7.486 .191 & 6.083 .631 & 1.402 .560 \\
$2006-7$ & 7.667 .384 & 6.162 .861 & 1.504 .523 \\
$2007-8$ & 7.598 .497 & 6.042 .829 & 1.555 .668 \\
$2008-9$ & 7.702 .749 & 6.071 .687 & 1.631 .062 \\
$2009-10$ & 7.735 .815 & 6.078 .510 & 1.657 .305 \\
$2010-11$ & 7.739 .239 & 6.073 .889 & 1.665 .350 \\
$2011-12$ & 7.769 .423 & 6.074 .988 & 1.694 .435 \\
$2012-13$ & 7.878 .538 & 6.156 .077 & 1.722 .461 \\
$2013-14$ & 7.803 .684 & 5.979 .455 & 1.824 .229 \\
$2014-15$ & 7.784 .625 & 5.934 .268 & 1.850 .357 \\
$2015-16$ & 7.446 .515 & & \\
\hline
\end{tabular}

Fuente: Memoria Educativa de Venezuela

Se expone de manera clara como ha venido descendiendo la matricula total en el sistema educativo formal a partir del periodo escolar 2005-2006, luego del repunte experimentado en el 2003. Ahora bien, lo más interesante de estas cifras es que, es en la escuela oficial donde el descenso es más 
pronunciado, mientras que la educación privada experimente un aumento año a año, leve pero sostenido. Esto se ha interpretado de múltiples formas (Memoria Educativa 2015).

La desaparición progresiva del Programa de Alimentación Escolar o su ineficiencia por la corrupción generalizada, ha eliminado uno de los mayores incentivos para que los sectores más pobres de la población enviaran sus niños a las escuelas. Ante el riesgo de sufrir desmayos por el hambre, las madres prefieren mantener a los niños en casa o ayudándola a conseguir alimentos en las interminables colas o filas que se hacen para hacerse de los escasos productos de la dieta diaria.

Otra razón tiene que ver con la precariedad de las condiciones de las escuelas oficiales. Muchas de ellas no cuentan con servicios de agua o tienen inservibles las instalaciones sanitarias por la falta de mantenimiento. La falta de profesores, sobre todo en educación media, ha llevado a la nefasta decisión de promediar las calificaciones obtenidas en las asignaturas donde tienen profesor para asignarlas en aquéllas donde carecen del docente. Así, un estudiante en Venezuela puede lograr una titulación de Bachiller sin haber nunca cursado asignaturas como matemática, química, física o biología. Al final obtienen un Título sin haber adquirido las competencias ni el conocimiento para ser exitosos en los exigentes estudios universitarios. El resultado, aumentan las tasas de deserción y abandono, sobre todo en el bachillerato. De hecho, las cifras aportadas por el Banco Interamericano de Desarrollo indican que en 2015, en Venezuela solo se graduaron de Bachiller apenas el 28,7\% del total de la población con edades entre 18 y 20 años, solo por encima de Brasil $(21,4 \%)$, Guatemala (20.1\%) y Costa Rica (19\%). En Chile, se gradúa el $80 \%$. El promedio en la región es de $43,1 \%$ por lo que, de acuerdo a este estudio, Venezuela está muy por debajo del promedio regional (CIMA-BID 2016).

De acuerdo con declaraciones publicadas en el Portal La Patilla.com, periódico digital de alta demanda en Venezuela, Juan Maragall, Director de Educación del estado Miranda y destacado investigador, alertaba que esta situación reflejaba la destrucción de un mito revolucionario que expandió el gobierno a través de su aparato propagandístico. Para Maragall, paradójicamente a lo que pregona el gobierno, son los más pobres los que no culminan sus estudios. En palabras de este experto el gobierno queda al desnudo en su discurso demagógico en tanto que "los más desfavorecidos son los que abandonan las aulas. Lo cual representa un fracaso simultáneo del Gobierno en calidad y equidad; y cuando los menos favorecidos son los que abandonan. Se puede decir que la escasez de calidad está produciendo altos niveles de injusticia social" (Maragall 2017).

Es bueno aclarar que, salvo las estadísticas aportadas por el BID, las cifras que presentamos en las tablas sobre dinámica matricular fueron extraídas de 
los cálculos realizados por los investigadores de la Línea de Investigación Memoria Educativa de Venezuela, adscritos al Doctorado en Educación de la Universidad Central de Venezuela. Estos investigadores se nutren de las cifras oficiales aportadas por las Memorias y Cuentas ministeriales y las aportadas por las páginas web de las instituciones gubernamentales.

\section{Universidad y revolución. Encuentros y Desencuentros}

Durante los primeros 3 años de gobierno del gobierno de Chávez las relaciones con las universidades autónomas podrían calificarse como de cordialidad y respeto mutuo. Sin embargo, a partir del año 2001 comienzan las tensiones por el empeño por parte del gobierno de imponerse a estas instituciones violentando su autonomía.

La primera escaramuza se presentó cuando estudiantes afectos al gobierno tomaron por la fuerza en abril de 2001, el Salón de Sesiones del Consejo Universitario de la Universidad Central de Venezuela, la primera universidad del país. Entre las pretensiones de este grupo estuvo designar por la vía de los hechos unas nuevas autoridades rectorales, desconociendo a las legalmente investidas. Esa toma duró aproximadamente 3 meses y contó con la ayuda logística del gobierno del presidente Chávez. Luego de estos 3 meses de situación irregular, la comunidad universitaria pudo desalojar a este grupo de estudiantes. Este fue el inicio de una serie de agresiones de todo tipo contra esta y el resto de las universidades autónomas. Solamente en la Universidad Central de Venezuela se han contabilizada en los últimos 15 años más de 100 incursiones violentas por cuerpos paramilitares y estudiantes identificados con el partido de gobierno.

Paralelamente, el gobierno revolucionario fue creando una treintena de universidades dependientes del ministerio de educación universitaria, o lo que es lo mismo decir, instituciones sin autonomía académica ni organizativa, con autoridades nombradas ejecutivamente por el ministro de turno y con prohibición expresa de crear organizaciones estudiantiles o sindicatos docentes. La creación de nuevas universidades y el cambio de estatus de los colegios universitarios e institutos tecnológicos a universidad, vino acompañado de una oferta demagógica de cupos sin requisito alguno de prueba o mecanismo de ingreso. A esto se suma la creación de la llamada Misión Sucre, sobre la que más arriba comentamos.

Esta explosión de instituciones e iniciativas menos formales como la Misión Sucre, que a partir del año 2003 nacieron con rango de universidades, se justificó bajo el argumento de la necesidad de saldar una deuda con los sectores más pobres de la sociedad. De esta manera la revolución cumplía uno de los anhelos de la juventud venezolana, a saber, tener acceso a la educación 
universitaria (Ramírez y Graffe 2010). Es bueno señalar que tal anhelo no se había cumplido por la limitada oferta de cupos en las universidades existentes, y por las dificultades para aprobar los mecanismos de ingreso de que estas instituciones implementaban por la limitada oferta de cupos. En la tabla siguiente se podrán constatar las incidencias de estas políticas sobre el aumento de la matrícula en educación superior.

\section{Tabla 4}

Matrícula en educación superior (1998-2015)

\begin{tabular}{cc}
\hline Años & Matrícula \\
\hline $\mathbf{1 9 9 8 - 9}$ & 796.350 \\
$\mathbf{1 9 9 9 - 0}$ & 818.438 \\
$\mathbf{2 0 0 0 - 1}$ & 852.850 \\
$\mathbf{2 0 0 1 - 2}$ & 881.501 \\
$\mathbf{2 0 0 2 - 3}$ & 1.260 .855 \\
$\mathbf{2 0 0 3 - 4}$ & 1.123 .063 \\
$\mathbf{2 0 0 4 - 5}$ & 1.247 .714 \\
$\mathbf{2 0 0 5 - 6}$ & 1.807 .122 \\
$\mathbf{2 0 0 6 - 7}$ & 2.135 .146 \\
$\mathbf{2 0 0 7 - 8}$ & 2.135 .000 \\
$\mathbf{2 0 0 8 - 9}$ & 2.200 .000 \\
$\mathbf{2 0 0 9 - 1 0}$ & 2.200 .000 \\
$\mathbf{2 0 1 0 - 1 1}$ & 2.340 .207 \\
$\mathbf{2 0 1 1 - 1 2}$ & 2.503 .296 \\
$\mathbf{2 0 1 2 - 1 3}$ & 2.600 .000 \\
$\mathbf{2 0 1 3 - 1 4}$ & 2.620 .013 \\
$\mathbf{2 0 1 3 - 1 4}$ & 2.622 .013 \\
$\mathbf{2 0 1 4 - 1 5}$ & 2.622 .013 \\
\hline
\end{tabular}

Fuente: Memoria Educativa Venezolana 
El número de estudiantes aumentó en casi 2 millones desde 1998 a 2015, lo cual colocó a Venezuela en uno de los países del mundo con mayor número de estudiantes universitarios. Sin embargo tales cifras, si bien reflejan una política de inclusión exitosa, no reflejan la calidad en la formación de estos estudiantes. Pero este es un tema difícil de analizar por la imposibilidad de acceder a datos o información académica de estas universidades. No se tiene acceso a los programas de estudios, ni a las estadísticas de ingreso, tasa de abandono y promoción de los nuevos profesionales. Lo que se ha podido conocer son las denuncias realizadas por eminentes médicos acerca de la escasa calidad académica y déficit comprobado de conocimientos en el área de la salud, de los llamados Médicos Integrales Comunitarios. Inclusive se tiene conocimiento de que en diciembre de 2016, 6 Médicos Integrales Comunitarios venezolanos reprobaron el EUNACOM (examen chileno para el ejercicio de la medicina), con calificaciones que no pasaban de 2 puntos, sobre un total 100 (El Pitazo 2017). Otro elemento que habla de la deficiente formación de estos profesionales es el hecho de que para poder cursar los postgrados de las facultades de medicina de las universidades autónomas tuvieron que recurrir al Tribunal Suprema de Justicia, solicitando un Amparo por la violación del derecho al estudio. Logrado el Amparo e inscritos en los postgrados, solo una ínfima parte ha logrado mantenerse como cursantes por las bajas calificaciones obtenidas.

Paralelamente a la creación y promoción de estas nuevas universidades con el atractivo de no aplicación de prueba vocacional o de aptitudes para determinar si se poseen las competencias necesarias para estudiar determinada carrera, el gobierno revolucionario a mantenido una política de acoso a las universidades autónomas a través de la asignación presupuestaria y el arrebato unilateral de la competencia autonómica para asignación de los cupos o plazas para los estudiantes.

Desde el año 2007 hasta la fecha (2017), el gobierno nacional no ha aumentado la cuota presupuestaria que por Ley le corresponde a estas casas de estudio. Bajo el argumento de la falta de recursos por la baja de los precios del petróleo, se ha recurrido a la figura del "Presupuesto Reconducido", que no es más que asignar el mismo monto del año anterior. Esto, en una sociedad altamente inflacionaria, ha constituido un severo golpe a la academia. Con esta política, destinada a hacer desaparecer a las universidades autónomas por no doblegarse a los dictámenes del régimen, el sector más afectado fue la investigación. Veamos.

En un estudio realizado por Ramírez y Salcedo (2015) en el cual se analizaron los datos del ranking Scimago sobre la productividad de artículos científicos en Venezuela, se constató que si bien hubo un incremento en ese rubro desde el año 2001, gracias a los incentivos derivados de programas 
gubernamentales como el PPI (Programa de Promoción al Investigador) y la aplicación de la Ley Orgánica de Ciencia y Tecnología aprobada en 2005, (por esta Ley las empresas aportaban entre 0,5 y 2,0\% del ingreso bruto anual para financiar proyectos de investigación), a partir del 2010 se ha venido observando un decrecimiento pronunciado de esta producción, la cual históricamente ha sido generada en un $80 \%$ por las universidades autónomas del país. Observemos en el gráfico siguiente, la producción de artículos científicos de Venezuela y de Colombia desde 1986 a 2014.

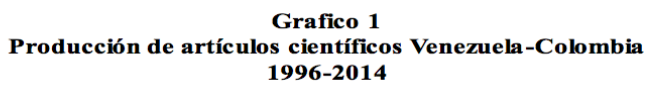

1996-2014

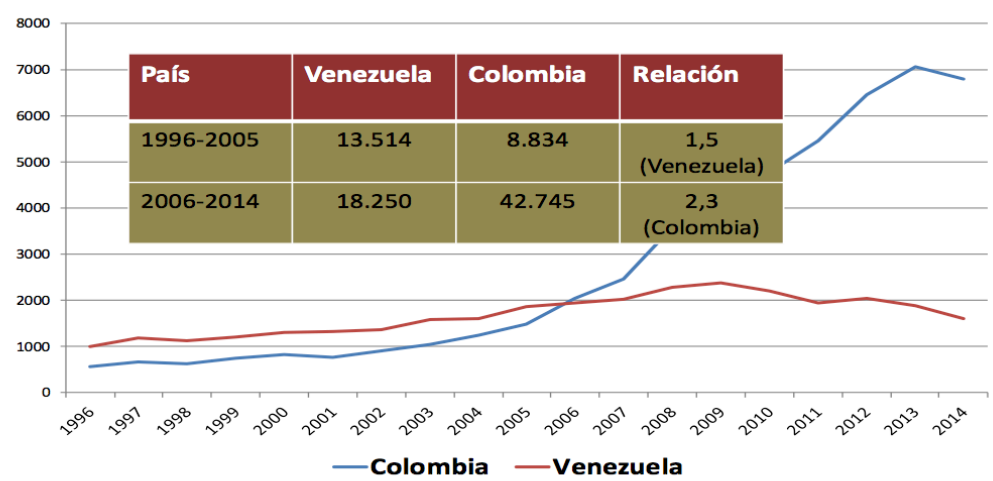

Fuente: Portal Scimago-2015. Procesamiento propio

Es evidente la caída en la generación de artículos científicos. Hasta 2005 por cada artículo publicado por Colombia, Venezuela publicaba aproximadamente 2 artículos, pero a partir de 2006 se cambia la relación a favor de Colombia. Por cada artículo hecho en Venezuela y publicado en prestigiosas revistas científicas del mundo, Colombia publica alrededor de 4, es decir duplica con tendencia a aumentar esta brecha (Ramírez y Salcedo 2015). Esto demuestra el deterioro de la academia venezolana. Este deterioro se ha visto agravado recientemente por la migración masiva de profesores universitarios con estudios de cuarto nivel a universidades extranjeras, en busca de mejores condiciones de vida. Para julio de 2017 en Venezuela, un profesor universitario con 16 años de servicio, con doctorado, publicaciones escritas y con el máximo escalafón alcanzable en la carrera docente recibe un salario equivalente a los 50 dólares mensuales al cambio del mercado negro, que es donde se consiguen estas divisas, y equivalente a 97 dólares de acuerdo al cambio oficial controlado por el gobierno y al cual muy pocos sectores privilegiados y afectos al gobierno, tienen acceso. A esto hay que anotar que, por efectos de la escasez y la inflación, los productos de la 
Cesta Básica que se consiguen en el mercado, tienen precios a dólar de mercado negro porque los comerciantes importan sus mercancías a ese dólar, por no tener acceso al oficial. Así, un profesor universitario con altísima productividad académica solo podría adquirir con su salario menos de un tercio de la Cesta Básica, la cual, para abril de 2017, tiene un precio de aproximadamente de Bs. 1.214.020,00 (173 dólares al cambio del mercado negro), esto según datos del Centro de Documentación y Análisis de los Trabajadores de la Federación Venezolana de Maestros (2017), que, aunque no es un organismo oficial, sus cifras se asemejan mucho a lo que se percibe en la economía diaria.

Así entonces un profesor universitario en cuya formación el Estado ha invertido tiempo y dinero, termina renunciando a su puesto de trabajo, para aceptar plazas en universidades de la región con salarios de 4000 o más dólares mensuales y en países con niveles de inflación de 1 dígito. Para el año 2017 se han verificado más de 1400 renuncias de profesores con credenciales de mérito, solo de dos de las universidades más prestigiosas del país como la Universidad Central de Venezuela y la Universidad Simón Bolívar. La cifra va en aumento, aunque en Venezuela es casi imposible conocerla a ciencia cierta.

Los efectos sobre la producción científica en el país son inconmensurables. Un estudio realizado por Ramírez y Salcedo (2016), da cuenta de cómo, a partir de la instauración de la revolución chavista en el poder en Venezuela, el aporte de este país al total de la producción elaborada en América Latina y el Caribe, ha ido descendiendo de manera continuada. Según las cifras aportadas por esta investigación, para 1998 Venezuela aportaba un 4,2\% del total de la producción generada en la región, esta cifra fue disminuyendo de manera constante durante el período de Hugo Chávez y se ha acentuado en la gestión del presidente Nicolás Maduro quien asumió el poder a partir de 2013. Los cálculos fueron realizados a partir de los datos aportados por la base de Datos Scimago de 2016. El gráfico siguiente habla por si solo. 
Gráfico 2

Aporte de la producción de papers de Venezuela a ALC (\%)

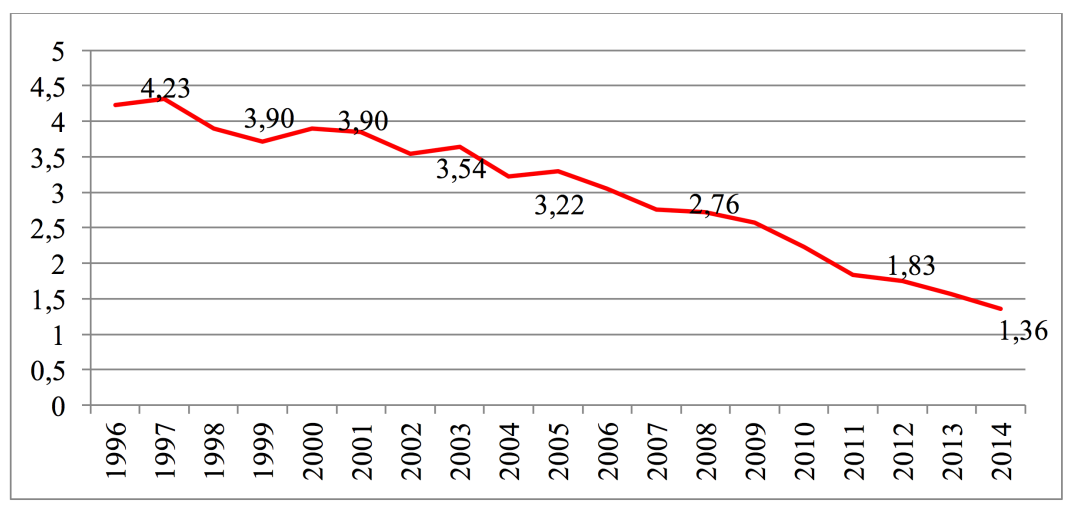

Fuente: Scimago. Cálculos propios

La investigación, cómo puede constatarse, ha sido la principal víctima de esta política de cerco a las universidades autónomas en Venezuela. Un dato importante y reciente es que en la propuesta de Asamblea Nacional Constituyente que propone de manera fraudulenta e inconstitucional el presidente Nicolás Maduro, se ha mencionado como uno de sus objetivos, la derogación de la autonomía universitaria. De concretarse esta propuesta, las 6 universidades donde se genera el $80 \%$ de la producción científica producida en el país, pasaran finalmente a ser controladas por un gobierno que ha implantado un modelo político que denigra de la meritocracia y que tiene una concepción del trabajo intelectual como residuo de los vicios generados por el capitalismo. Ese es el futuro cercano que le espera a la universidad venezolana de materializarse el socialismo del siglo XXI, que no es más que una mala copia del socialismo del siglo XX que ha fracasado en todos los países donde se ha impuesto a sangre y fuego.

\section{Conclusión: La revolución bolivariana ha construido una pobre educación para los pobres}

Una panorámica de la educación venezolana en tiempos de revolución chavista deja un saldo negativo. Las políticas públicas chavistas no apuntaron al mejoramiento de la calidad educativa. Por el contrario, la demagogia y el uso de la escuela como espacio para la ideologización y la partidización de los sectores más vulnerables de la sociedad (niños y adolescentes), ha signado 
todo este período. Las promesas de inclusión y de una educación de calidad para todos, muy tempranamente cayeron en el olvido. Si bien es cierto que la matrícula escolar aumento a cifras importantes, no fue acompañada por políticas que garantizaran que en las escuelas públicas donde asisten los más pobres, se impartiera una educación de igual o superior calidad a la impartida en los más emblemáticos colegios privados de Venezuela. El gobierno no llego hasta allí, quizás por temor a lo que manifestó el exministro de Educación Héctor Rodríguez: "no crean que los vamos a educar a todos para que después mejoren sui posición social y se conviertan en escuálidos". Para que el lector pueda interpretar correctamente esta declaración pública de este alto funcionario del gobierno, debe saber que "escuálidos", fue la expresión con la que Chávez estigmatizó a todo aquél que disintiera de su proyecto político.

No se exagera ni se peca de insidioso cuando se afirma que la educación que se gestionó desde la concepción del denominado socialismo del siglo XXI, pasó de tener una calidad medianamente aceptable (basta con escuchar los constantes reconocimientos a nuestros graduados universitarios en el exterior), a ser una educación de dudosa calidad. Debemos confesar que esta afirmación tan taxativa no está respaldada por datos o investigaciones que así lo corroboren. El gobierno nacional y sus autoridades educativas a todos los niveles son reacios a suministrar datos y no permiten el acceso a las escuelas públicas para conocer de primera mano la situación de aprovechamiento académico de nuestros estudiantes. Vale la pena anotar que el gobierno nacional eliminó desde el año 2002 los mecanismos de evaluación de los aprendizajes que se diseñaron desde una de las oficinas ministeriales, además se ha negado rotundamente a participar en las pruebas PISA, lo que impide saber el rendimiento de nuestros estudiantes en comparación con el de sus pares en la región y el mundo. Sin embargo, pese a esta política de ocultar información, existen indicadores que señalan que la educación de los niños y adolescentes venezolanos, sobre todo los de los sectores más pobres, ha bajado estrepitosamente de calidad durante la llamada revolución humanista.

El inventario para llegar a esta conclusión pesimista con respecto a la educación en Venezuela está a la vista: la mayoría de los bachilleres de los liceos públicos no tienen la más mínima posibilidad de enfrentar exitosamente ningún mecanismo de evaluación para ingresar a las universidades de mayor prestigio en el país; un circuito escolar (las Misiones) que se constituyeron en una pobre educación para los pobres; rezago en el uso educativo de las nuevas tecnologías; poco o ningún estímulo para el estudio y ejercicio de la carrera docente por los precarios salarios y peores beneficios socioeconómicos, amén de las preocupantes cifras de deserción escolar que está revirtiendo la política de inclusión que impulsó el gobierno a sus inicios. A todo esto, se le suma la poca inversión en construcción de escuelas y en el mantenimiento de las 
existentes. Para el día de hoy hacen falta por lo menos 4000 escuelas en todo el país y todo apunta a que esta deuda social no será saldada en los próximos años por las graves condiciones económicas en las que se encuentra el país gracias a la pésima administración de sus recursos.

Cómo explicar tanto descuido y desinversión social en materia educativa en los últimos 18 años? Pensamos que no se trata sólo de ineptitud y falta de conocimiento sobre la realidad educativa del país. Todo apunta a que la finalidad que le ha atribuido la revolución a la educación es la que le ha dado coherencia a estas políticas aparentemente reñidas con los estándares de excelencia que exige el mundo globalizado de hoy. La desvalorización de la meritocracia en aras de un pretendido "diálogo de saberes", no ha hecho más que minimizar la fuerza de la ciencia y la tecnología bajo el argumento de estar "al servicio del capitalismo". Con discursos como este, difícilmente podremos aspirar a construir un sistema educativo capaz de generar los talentos que mañana puedan sustituir al petróleo como la materia prima más importante y rentable del país.

Qué nos espera en materia educativa?. Para julio de2017 se concretó lo que la oposición venezolana llamó un "Gran Fraude Electoral” con la elección de una Asamblea Constituyente electa de manera inconstitucional y poco transparente. Esta ANC conformada totalmente por militantes de la revolución debido a la no participación de otras opciones políticas, promete materializar propuestas que afectarán de manera radical a la educación venezolana. Los candidatos en su campaña electoral han anunciado acabar con la autonomía de las universidades y la educación privada, entre otras, medidas de control sobre la ciudadanía. De no cambiarse el modelo político que se pretende profundizar a partir de la nueva constitución que crea el Estado Comunal, difícilmente la educación podrá salir de la postración en la cual se encuentra. El modelo político sovietizante que se quiere imponer, coloca a la escuela a su exclusivo servicio y no al servicio del ciudadano.

Para el régimen impuesto en Venezuela desde 1999, la escuela se erige como el taller para moldear conciencias y sensibilizar almas en torno a un proyecto político partidista. Bajo este esquema la formación profesional es colateral y siempre en función de las necesidades planteadas por el Estado-Partido. ¡Qué sean como el Che!, decía Fidel en alusión al ideario de la educación en la isla caribeña, en Venezuela el eslogan es ¡Qué sean como Chávez! (tal como lo manifestó a la prensa nacional la ex Jefe de Gobierno de Caracas Jaqueline Farías, con motivo de la remodelación de una escuela en 2007). Ese será la educación que le espera a las generaciones nacidas en revolución. 


\section{Referencias bibliográficas:}

Aguirre, Martha; Ramírez, Tulio; Carvajal, Leonardo; Ugalde, Luis (2015) Política e Ideología en los textos escolares. Caracas: CERPE-UCAB.

Asamblea Nacional Constituyente (1999). Constitución de la República Bolivariana de Venezuela. Gaceta Oficial de la República Bolivariana de Venezuela No 5.453 (Extraordinario), Caracas, 24 de marzo de 2000.

Asamblea Nacional (2013) Plan de la Patria. Plan de Desarrollo Económico y Social de la Nación 2013-2019. Caracas: Correo del Orinoco.

Bracho Arcila, A. y León de Hurtado, M. E. (2011). Venezuela y su gente. Ciencias Sociales 6to. Grado. Ministerio del Poder Popular para la Educación. Caracas: Imprenta Nacional.

Bracho Arcila, A. y León de Hurtado, M. E. (2014). Venezuela y su gente. Ciencias Sociales 6to. Grado. Ministerio del Poder Popular para la Educación. Caracas: Equipo Editorial: Colección Bicentenario.

Bravo Jauregui, Luís (2006). La educación en tiempos de Chávez. Caracas: Ediciones de El Nacional.

CENDAS-FVM (2017) Canasta Básica subió a 1.214.020,20 bolívares en abril. Finanzas Digital.

CEOFANB (2016) Instructivo No. 001-16. El soldado valiente bolivariano.

CERPE (2015) La Consulta por la Calidad Educativa. Disponible en: http:// www.cerpe.org.ve/noticias-lector-principal/items/315.html. [Consultado el 01 de agosto de 2017]

CIMA-BID (2017) Base de Datos. Disponible en: http://www.iadb.org/es/ bases-de-datos/cima/inicio,20590.html?

Galicia, Hernán (2016) Min Defensa ejecuta plan para adoctrinar a niños y jóvenes en escuelas públicas. El Nacional, 18 de abril de 2016, Disponible en: http://www.el-nacional.com/politica/Min-Defensa-adoctrinar-escuelaspublicas_0_831516928.html. [Consultado el 24 de julio de2017]

Graffe, Gilberto (2005). Politicas públicas educativas frente a la crisis, reforma del estado venezolano y modernización de la educación venezolana 19792002. Caracas: Secretaría - Vicerrectorado Académico de la Universidad Central de Venezuela.

Gramsci, Antonio (2007) Cuadernos de la prisión. Roma: Einaudi.

Instituto Nacional de Estadísticas (2011) Censo de Población y Viviendas. Disponible en: http://www.ine.gov.ve/index.php?option=com_content\&v iew=category\&id=95\&Itemid. [Consultado el 30 de julio de 2017].

Memoria Educativa Venezolana (2015) La escolaridad y la inversión educativa en Venezuela 2015. Disponible en: www.cerpe.org.ve/tl.../Actualidad $\% 20$ Educativa/1-\%20INFORME\%20\%202015.pdf. [Consultado el 13 de julio de 2017]. 
Ministerio de Educación Cultura y Deportes (2004) Resolución Nro. 47 (Creación de la Misión Ribas), (junio, 09 de 2004), Gaceta Oficial de la República Bolivariana de Venezuela, $N^{\circ}$ 37.957. Caracas, 10 de junio de 2004.

Ministerio del Poder Popular para la Educación (2011) “Colección Bicentenario. Un logro en materia de educación liberadora. Disponible en: http:// es.scribd.com/doc/98665328/Collecion-Bicentenaria. [Consultado el 12 de julio de 2017].

Ministerio del Poder Popular para la Educación (2015) Proceso de cambio curricular en educación media. Documento general de sistematización de las propuestas pedagógicas y curriculares surgidas en el debate y discusión. Disponible en: http://www.cerpe.org.ve/tl_files/Cerpe/ contenido/documentos/Actualidad $\% 20$ Educativa/Formacion $\% 20$ Tecnica/PROCESO \%20DE\%20CAMBIO\%20CURRICULAR $\% 20$ (PRIMERA\%20VERSION)(1).pdf. [Consultado el 30 de julio de 2017].

Ministerio del Poder Popular para la Educación Superior (2008). Resolución $N^{\circ} 3149$ (Creación del Programa Nacional de Formación en Medicina Integral Comunitaria). Gaceta Oficial de la República Bolivariana de Venezuela, $N^{\circ} 39.032$. Caracas, 7 de octubre de 2008.

Presidencia de la República (2003) Se designa la Comisión Presidencial de Misión Robinson (Gaceta Oficial Nro. 37.702, Decreto del Ejecutivo No. 2434 del 02-06-03).

Presidencia de la República Bolivariana de Venezuela (2003). Decreto Presidencial № 2604 (Creación de la Misión Sucre), (09 de septiembre de 2003). Gaceta Oficial de la República Bolivariana de Venezuela $\mathrm{N}^{\circ}$ 37.772, Caracas, 10 de septiembre de 2003.

Presidencia de la República Bolivariana de Venezuela (2004) (Gaceta Oficial Extraordinaria $\mathrm{N}^{\circ} 37865$, Decreto $\mathrm{N}^{\circ} 2745$ de fecha 26-01-04, mediante el cual se crea la Comisión Presidencial para la implementación y coordinación institucional del programa denominado Barrio Adentro.

Páez, Tomas (Coord.) (2015) La voz de la diáspora venezolana. Madrid: Catarata.

Peñaloza, Pedro Pablo (2013, noviembre, 7) Advierten que el currículo bolivariano viola la constitución. (El Universal, entrevista a Tulio Ramírez y Leonardo Carvajal). Disponible en: http://venezuelaawareness. com/2013/11/advierten-que-el-curriculo-bolivariano-viola-laconstitucion/. [Consultado el 4 de agosto de 2017].

Quintero, I. (2014) Enseñar Historia: 7 anotaciones sobre la Colección Bicentenario".Prodavinci.Disponibleen: http://prodavinci.com/2014/05/27/ actualidad/ensenar-historia-7-anotaciones-sobre-la-coleccion-bicentenariopor-ines-quintero/ [Consultado el 19 de agosto de 2014]. 
Ramírez, Tulio (2007). Del control estatal al libre mercado. Políticas Públicas y textos escolares en Venezuela (1958-2005). Caracas: EBUCV.

Ramírez, Tulio (2009). Los circuitos escolares y el ingreso a la educación superior en Venezuela. Revista Docencia Universitaria. X, (1). pp. 65-85.

Ramírez, Tulio y Graffe, Gilberto (2010) Intentando saldar una deuda social. La inclusión en la educación superior venezolana. Revista Fermentum, 20, (58). 261-288.

Ramírez, Tulio (2012) El texto escolar como arma política. Venezuela y su gente. Ciencias Sociales, 6to grado. Revista Investigación y Postgrado. 27 (1). 163-194.

Ramírez, Tulio y Salcedo, Audy (2015) La visibilidad de la universidad venezolana según datos del ranking Scimago 2015". Anuario ININCO. (27). 253-281.

Ramírez, Tulio (2016) ¿Enseñar la Historia o Reconstruir la Historia? Los textos escolares de Ciencias Sociales de la Colección Bicentenario. Revista Fermentum. 26, (77). 160-167.

Ramírez, Tulio y Audy Salcedo. (2016) Inversión y productividad científica en Venezuela. ¿Una relación inversamente proporcional? Revista de Pedagogía, 37 (101). 147-174.

República Bolivariana de Venezuela (2015) Ley de Presupuesto para el Ejercicio Económico 2016. Disponible en: http://www.onapre.gob.ve/index.php/ publicaciones/descargas/finish/56-titulo-ii/611-ley-de-presupuesto-2016titulo-ii. [Consultado el 14 de julio de 2017].

Rodríguez, Nayrobis (2017). MinSalud y las deficiencias de personal médico en Venezuela. Periódico Digital El Pitazo, 15 de julio de 2017.

San Blas, Gioconda (2016) ¿Educación Militar? ¡Somos civiles!. Diario Tal Cual Digital. Disponible en: http://www.talcualdigital.com/Nota/125321/ educacion-militar-somos-civiles?fb_comment_id=1041928855899030_1 042055685886347\#f3f0b29fd4f8a06. [Consultado el 17 de julio de 2017]]. 